\title{
Characterizing the quality-of-life impact of Duchenne muscular dystrophy on caregivers: a case-control investigation
}

\author{
Carolyn E. Schwartz ${ }^{1,2^{*}} \mathbb{D}$, Roland B. Stark', Ivana F. Audhya ${ }^{3}$ and Katherine L. Gooch ${ }^{3}$
}

\begin{abstract}
Background: This study examined the impact of Duchenne muscular dystrophy (DMD) on family-member caregivers in terms of quality of life, life stress, and indirect costs, as compared to a stratified comparison group of parents of similar-age children without DMD.

Methods: A web-based survey included DMD caregivers and a nationally representative comparison group of parents of children without DMD stratified by Child Age Group. Outcomes included quality of life, resilience, caregiver impact, stressful life events, financial strain, out-of-pocket expenditures, work productivity and unrealized ambitions. General linear models assessed the main effect of Caregiver Group and the interaction of Caregiver Group with ChildAge-Group, after adjusting for demographic covariates.
\end{abstract}

Results: Compared to parents without a DMD child, DMD Caregivers reported better physical health but worse mental health, positive affect/well-being, environmental mastery, difficulty paying bills, and more hours missed from work. Providing caregiving support for DMD teenagers was the most challenging. DMD caregivers curtailed their educational and professional ambitions, and modified their homes to accommodate the disability associated with DMD. Their non-DMD children had to make sacrifices as well. Nonetheless, in resilience and life stress, DMD caregivers were comparable to the comparison group, and showed consistent levels of positive emotions across the age of their DMD child.

Conclusion: DMD caregivers fared worse on most outcomes and faced more hurdles in work life. They face constraints and hidden costs that impact their health and financial well-being. Caregivers of teenagers with DMD reported higher impact. Nonetheless, parents of DMD children of all ages maintained notable resilience and positivity.

Keywords: Duchenne muscular dystrophy, Impact, Caregivers, Quality of life, Resilience

\section{Introduction}

Taking care of others is a common part of adult life, particularly as parents. For many, helping others benefits their own health-related quality of life (HRQOL) [1], providing a greater sense of purpose in life [2,3], enhancing mental health $[4,5]$ and, among females, enhancing physical health $[5,6]$. When helping others becomes

\footnotetext{
*Correspondence: carolyn.schwartz@deltaquest.org

1 DeltaQuest Foundation, Inc, 31 Mitchell Road, Concord, MA 01742, USA Full list of author information is available at the end of the article
}

less occasional and develops into a time- and energydemanding long-term role, then the "caregiving" can become a burden. Providing caregiving support to aging parents, sick spouses/partners, or chronically-ill children has been reported to have direct and deleterious effects on the caregiver's health and work productivity [7-12]. Caregiver burden in a range of progressive neurologic diseases has been found to be associated cross-sectionally with the patient's cognitive and executive-functioning status $[13,14]$ and sleep problems [15], and longitudinally with the patient's anxiety and depression [16-18]. 
While there are general truths about the challenges of chronic caregiving, each caregiving context has its unique challenges. For Duchenne muscular dystrophy (DMD), the challenges of caregiving rise above the challenges of usual parenting and likely relate to the early age of diagnosis, progressive disease trajectory, life domains affected, and truncated life expectancy. DMD is a progressive, rare, and irreversible neuromuscular disorder occurring primarily in males -- 1 in 5050 live births [19-21]. Usually diagnosed by age 5 , the disorder presents as delayed development that includes motor difficulties [22], and may include cognitive impairment and attention-deficit disorders [23]. On average by age $10-12$, progressive muscle weakness leads to individuals' loss of ambulation, upper-limb function problems, and comorbid conditions such as scoliosis and muscular contractures [22]. By age 15 , individuals often experience increased difficulty breathing and life-threatening heart and lung conditions [24]. People with DMD face profound uncertainty regarding lifespan, typically dying in their 20 s to early 30s [24], although medical advances [19] have led to longer life expectancies [25].

A number of published articles have addressed the impact of DMD on family-member caregivers [26] including healthy siblings [27, 28]. Caregiving demands increase with DMD progression [29] and low patient vitality and mental health [30], and this demand impairs multiple domains of caregivers' health-related QOL [26, 30], including sleep quality [31], mental health [11, 32, 33], social [34] and sexual functioning [35], and work productivity [36]. Although these studies provide helpful descriptive information, they are primarily cross-sectional 'snapshots' of impact, many using generic tools that may have missed important domains and aspects of impact specific to DMD. Further, only one of 25 papers examined included a comparison group, and the sample sizes were generally small [31]. The literature has not reported caregiver impact by the different phases (i.e., stages) of DMD separately in estimating impact. To study the impact of DMD caregiving fully, one needs to ensure robust sample sizes across age groups that reflect disability progression over time. In this way, caregiver impact can be investigated separately by each phase or stage of DMD.

The present study is descriptive and seeks to address the abovementioned gaps in the literature. It examines the impact of DMD on family-member caregivers in terms of QOL, life stress, and indirect costs. DMD caregivers are compared to a stratified group of parents of similar-age healthy children.

\section{Methods}

\section{Sample and procedure}

This study recruited DMD-caregiver participants via Rare Patient Voice (www.rarepatientvoice.com), patient-advocacy groups, and the snowball technique [37] (i.e., word of mouth). Comparison-group participants were recruited via IPSOS-Insight, LLC (www. ipsos.com), and were selected to accurately represent the United States in age, race/ethnicity, gender, and region. Eligible participants were age 18 or older, able to complete an online questionnaire, and (for DMD caregivers only) providing caregiving support to a family member with DMD at least two years old.

Telephone interviews were conducted with 15 DMD parent-caregivers to pretest and adapt possible measures for content validity and to develop items assessing out-of-pocket expenditures and impact on siblings (described in Measures below). These interviews shared initial proposed questionnaires as web-based surveys for the interviewee to complete prior to the interview. The interviewer then asked in the interview whether these questionnaires addressed relevant topics. The questionnaires were then modified and pre-tested with other interviewees, with similar content-validity queries. The final set of questionnaires addressed suggestions and concerns raised by the interviewees. The subsequent web-based survey was administered June through November 2020 through the HIPAA-compliant, secure Alchemer engine (www. alchemer.com).

Recruitment was stratified by Child Age Group: $2-7,8-12,13-17$, and $>=18$, reflecting the abovedescribed disability trajectory [22-25]. Although DMD can progress at varying rates, these age strata reflected the phases of DMD progression: ambulatory phase (up to age 7), transitional phase (up to age 12), and non-ambulatory phase (age $>=13$ ), with increasing dependence and involvement of other systems into adulthood (age $>=18$ ). If caregivers were providing caregiving support for more than one person with DMD, they were asked to report on the eldest or most disabled (the "index patient"). Participants with motor, visual, and/or other problems that made it difficult for them to complete the web-based survey instrument enlisted the assistance of a household member to enter their answers. Caregivers were paid $\$ 75$ honoraria to compensate them for their time completing the survey. The protocol was reviewed and approved by the New England Independent Review Board (NEIRB \#20201623), and all participants provided informed consent prior to beginning the survey. 


\section{Measures}

Unless otherwise noted, the measures described below were collected from all study participants. A subset of measures that were relevant only to DMD were collected only from DMD caregivers.

Quality of Life was assessed using a battery of brief, standardized tools. The PROMIS-10 General Health is a ten-item measure that yields scores for physical and mental health [38]. The NeuroQOL Positive Affect and Well-Being is a 9-item measure of well-being [39]. The Ryff Environmental Mastery is a 7-item subscale of the Ryff Psychological Well-Being measure that assesses how well the individual feels able to deal with the demands of her/his environment [40]. The Centers for Disease Control (CDC) Healthy Days Core Module [41] was used to operationalize resilience (see Statistical Analysis below). In this measure, two items ask the respondent to indicate how many days of the past 30 days their physical health (Physical Health Problems) or mental health (Mental Health Problems), respectively, was not good. A third item, Activities of Daily Living Impaired (ADL Impaired) asks how many days of the past 30 the respondent's poor physical or mental health kept them from doing their usual activities, such as self-care, work, or recreation.

Caregiver impact was assessed only in the DMD caregivers, using a DMD adaptation of the Hemophilia Caregiver Impact measure [42, 43]. Items were modified to reference DMD and were pretested for content via the telephone interviews. The resulting 39-item DMD Caregiver Impact Measure (DCI) includes seven negative-impact subscales (Practical, Physical, Financial, Symptom, Lifestyle, Social, and Emotional) and one positive-impact subscale (Positive Emotions).

Life stress was measured using a subset of items from the Urban Life Stress Inventory [44, 45]. The present study included a list of 18 areas of life, and the respondent was asked to indicate how much stress s/he experienced during the past 12 months using a five-level rating scale (no stress to extreme stress).

Financial strain was measured by an item asking about the respondent's difficulty paying bills [46]. Research to date suggests that this item yields fewer missing values than a question about household income [46] and is a better indicator of financial well-being because it directly assesses ability to make ends meet [47].

Indirect costs of DMD were operationalized as outof-pocket expenditures, work productivity, and unrealized ambitions. Out-of-pocket expenditures, assessed only in DMD caregivers, included eight home and vehicle modifications that might have been implemented to accommodate their child's DMD. Work productivity was operationalized using an item about hours missed from work in the past week, from the Work Productivity and
Activity Impairment measure [9, 48-50]. Unrealized ambitions were operationalized using statistical modeling (see below) that included the DeltaQuest Reserve-Building (DQRB) measure's [51] Occupational Complexity Index and the respondent's educational attainment. Occupational complexity was assessed using questions querying the job that was closest to the respondent's current or past occupation, which were then scored for complexity using the Occupational Information Network (O*NET) system [52]. Under this comprehensive, in-depth job-classification system, scores range from low complexity [1] to high complexity [5]), with higher scores reflecting more training and skills required to perform that occupation [53]. Some caregivers were unemployed and/or never employed because of their caregiving responsibilities, and they were assigned an $\mathrm{O}^{*} \mathrm{NET}$ value of " 2 " reflecting their role as caregiver. An $\mathrm{O}^{*} \mathrm{NET}$ value of " 2 " is the score used for caregivers in the O*NET data base (e.g., certified nursing assistant, home health aide, nurse's aid). Educational attainment summarized level of formal education, ranging from less than 12th grade to doctoral degree. Finally, Impact on Siblings, assessed only in DMD caregivers, queried nine rating-scale statements ranging from strongly disagree [1] to strongly agree [7] that related to sacrifices mentioned by caregivers in the above-mentioned interviews.

Demographic characteristics included year of birth, gender, race, ethnicity, education, marital status, weight, height, with whom the person lives (which yielded a count of people living in the household who could provide caregiving support), number of children, number of children with DMD (if applicable), smoking or vaping status, employment status, caregiver's and index child's comorbidities, source of referral to the study, and Zone Improvement Plan (ZIP) code. The comorbidities listed for the index child were selected on the basis of documented higher prevalence in people with DMD $[22,23]$.

COVID-19 specific information included whether anyone in the household was or had been infected with the novel coronavirus-2019, and rating scale items on COVID impact related to financial hardship, isolation, social support, and continuity of healthcare.

\section{Statistical analysis}

Descriptive statistics were used to summarize concepts measured only in DMD caregivers. When concepts were measured in both groups, $\mathrm{t}$-tests or chi-squared statistics were used to compare groups, and such concepts were also included in the general linear modeling.

Demographic differences between the two caregiver groups were controlled using propensity scores when we tested for differences in outcomes. A logistic regression model was computed predicting the dependent variable 
Group (DMD vs. comparison caregiver) from the following nine caregiver covariates: age, gender, race, Hispanic ethnicity, marital status, body mass index, number of people living in the household who could provide caregiving support, smoking/vaping status, and total number of children in the household. For $12 \%$ of participants, propensity scores based on the above were missing data and so were assigned in a subsequent model using the six predictors above that were missing no data.

To operationalize resilience, we built on a precedent for using residual modeling to infer resilience based on the behavior of other variables in the model [54-56]. This approach has been used in multiple studies of chronically-ill people and their caregivers [47, 57, 58]. The approach involves regressing the CDC Healthy Days ADL Impaired on Physical Health Problems, Mental Health Problems, and their interaction. The residuals from the regression model were saved and multiplied by negative one $(-1)$. Thus, a high resilience score reflects "over-performance", or more days than expected that the respondent was able to function despite physical or mental health problems or their synergistic effect [57]. Accordingly, a low resilience score reflects "under-performance", or fewer days than expected that the respondent was able to function despite such problems.

Group differences on outcomes were investigated using general linear modeling. To test the hypothesis that DMD caregivers had different outcomes than comparison caregivers, analysis-of-covariance models included as independent variables Group and propensity score and predicted the following dependent variables: QOL (physical and mental health, positive affect \& well-being, environmental mastery), resilience, stress, financial strain, and time missed from work. A separate set of models built on the above by adding the variable Child Age Group (referent category: child age 2-7) and an interaction term of Group * Child Age Group. These latter models examined whether DMD caregivers' predictive relationships were different from comparison caregivers' as a function of the DMD index child's age.

To operationalize Unrealized Ambitions, general linear modeling predicted the $\mathrm{O}^{*} \mathrm{NET}$ score (Occupational Complexity as dependent variable) from independent variables Group, Educational Attainment, their interaction, and the propensity score. In a subsequent model, Child Age Group and its interaction with Group were also included. Finally, an ordinal regression model was tested predicting caregiver educational attainment from Group and from ZIP-code-based population percentages of people who had vocational training/some college, a bachelor's degree, and a graduate degree. This latter model compared the caregivers' educational attainment to their communities' norms.
IBM SPSS version 27 [59] was used for all analyses.

\section{Results \\ Sample}

The study sample included 566 DMD caregivers and 594 comparison caregivers, representing nearly equally the four Child Age Group strata (see Additional file 5: Figure S1). The first three tables provide the univariate characteristics of the study samples; p-values from t-tests or chi-squared statistics assessing their differences; and explained variance (eta- or phi-squared) for those differences with $p<0.05$. We dealt with the issue of multiple comparisons by focusing on explained variance only when $p<0.05$ and in this way were selective about interpreting differences. The explained variance is mentioned parenthetically below. Whether due to DMD caregiving or other unmeasured factors, we found a number of small and medium effect-size differences between the two groups using Cohen's criterion [60] (i.e., explaining $1.0-5.9 \%$ or $6.0-13.9 \%$ of the variance, respectively).

\section{Demographics}

The DMD caregivers were younger than the comparison group (1\% explained variance), more likely to be female $(4 \%)$, more likely to be married or cohabiting and not divorced or widowed (1\%), and less likely to be Hispanic $(0.4 \%)$ (Table 1$)$. The DMD caregivers reported fewer comorbidities (1\%), including less frequent reports of back pain (1\%), diabetes (3\%), and high blood pressure $(2 \%)$. While the two groups were similar in terms of body mass index, DMD caregivers were less likely to have smoked or vaped, whether recently or in the past (7\%). DMD caregivers were less likely to be employed or retired and more likely to be unemployed (7\%) and, among those who worked, were less likely to work 30 or more hours per week (4\%).

Regarding the differential impact of the COVID-19 pandemic, DMD caregivers' households were less likely than the comparison group's to have been infected with COVID-19 (explained variance 4\%), and the former reported less financial hardship during the pandemic specifically (2\%) (Table 1 ). There were no differences in terms of social support, sense of isolation, or continuity of healthcare.

\section{Adjusting for Demographic Differences via Propensity Scores}

Given the above many demographic differences, the use of propensity scores helped control for variables that could have confounded observed group differences on outcomes. The propensity scores explained $11-15 \%$ of the variance in the data from the Cox \& Snell and Nagelkerke pseudo- $\mathrm{R}^{2}$ statistics, respectively. The 
Table 1 Descriptive Statistics of Caregivers

\begin{tabular}{|c|c|c|c|c|c|c|c|c|c|c|}
\hline \multirow[t]{2}{*}{ Variable } & \multicolumn{4}{|c|}{ DMD caregivers $(n=566)$} & \multicolumn{4}{|c|}{ Comparison caregivers $(n=594)$} & \multirow{2}{*}{$\begin{array}{l}p \text { from } T \text { - or } \\
\text { chi-square } \\
\text { test }\end{array}$} & \multirow{2}{*}{$\begin{array}{l}\text { Variance } \\
\text { explained If } p \\
<.05\end{array}$} \\
\hline & Mean & SD & Min & $\operatorname{Max}$ & Mean & $S D$ & Min & Max & & \\
\hline Age & 41.6 & 8.8 & 21 & 72 & 43.8 & 11.7 & 20 & 77 & $<0.0005$ & 0.01 \\
\hline Gender & Frequency & $\%$ & & & Frequency & $\%$ & & & $<0.0005$ & 0.04 \\
\hline Male & 140 & $25 \%$ & & & 267 & $45 \%$ & & & & \\
\hline Female & 426 & $75 \%$ & & & 327 & $55 \%$ & & & & \\
\hline Marital status & & & & & & & & & 0.04 & 0.01 \\
\hline Never married & 31 & $5 \%$ & & & 44 & $7 \%$ & & & & \\
\hline Married & 453 & $80 \%$ & & & 454 & $76 \%$ & & & & \\
\hline Cohabitation/domestic partner & 40 & $7 \%$ & & & 31 & $5 \%$ & & & & \\
\hline Separated & 11 & $2 \%$ & & & 9 & $2 \%$ & & & & \\
\hline Divorced & 23 & $4 \%$ & & & 45 & $8 \%$ & & & & \\
\hline Widowed & 5 & $1 \%$ & & & 10 & $2 \%$ & & & & \\
\hline Missing & 3 & $1 \%$ & & & 1 & $0 \%$ & & & & \\
\hline \multicolumn{11}{|l|}{ Race (check all that apply) } \\
\hline Black & 47 & $8 \%$ & & & 69 & $12 \%$ & & & 0.06 & \\
\hline White & 519 & $92 \%$ & & & 525 & $88 \%$ & & & 0.05 & \\
\hline Other & 21 & $4 \%$ & & & 49 & $8 \%$ & & & NA & \\
\hline Hispanic ethnicity & & & & & & & & & 0.045 & 0.004 \\
\hline Yes & 57 & $10 \%$ & & & 83 & $14 \%$ & & & & \\
\hline No & 490 & $87 \%$ & & & 495 & $83 \%$ & & & & \\
\hline Missing & 19 & $3 \%$ & & & 16 & $3 \%$ & & & & \\
\hline Level of education & & & & & & & & & $<0.0005$ & 0.11 \\
\hline Less than 12 th grade & 6 & $1 \%$ & & & 2 & $0 \%$ & & & & \\
\hline High school diploma & 59 & $10 \%$ & & & 54 & $9 \%$ & & & & \\
\hline Technical (Vocational) degree & 66 & $12 \%$ & & & 15 & $3 \%$ & & & & \\
\hline Some college & 92 & $16 \%$ & & & 83 & $14 \%$ & & & & \\
\hline 2-year University degree & 89 & $16 \%$ & & & 51 & $9 \%$ & & & & \\
\hline 4-year University degree & 171 & $30 \%$ & & & 188 & $32 \%$ & & & & \\
\hline Masters degree & 53 & $9 \%$ & & & 183 & $31 \%$ & & & & \\
\hline Doctoral degree & 5 & $1 \%$ & & & 18 & $3 \%$ & & & & \\
\hline Missing & 25 & $4 \%$ & & & 0 & $0 \%$ & & & & \\
\hline Recruitment Source & & & & & & & & & NA & \\
\hline Rare patient voice & 49 & $9 \%$ & & & 0 & $0 \%$ & & & & \\
\hline Patient advocacy groups & 87 & $15 \%$ & & & 0 & $0 \%$ & & & & \\
\hline Word of mouth & 428 & $76 \%$ & & & 0 & $0 \%$ & & & & \\
\hline IPSOS & 0 & $0 \%$ & & & 594 & $100 \%$ & & & & \\
\hline \multirow[t]{2}{*}{ Missing } & 2 & $0 \%$ & & & 0 & $0 \%$ & & & & \\
\hline & Mean & SD & Min & Max & Mean & SD & Min & Max & & \\
\hline Comorbidities, out of 15 presented & 1.3 & 1.7 & 0 & 9 & 1.6 & 1.7 & 0 & 10 & $<0.01$ & 0.01 \\
\hline Specific Comorbidities* & Frequency & $\%$ & & & Frequency & $\%$ & & & & \\
\hline Arthritis & 76 & $13 \%$ & & & 85 & $15 \%$ & & & 0.45 & \\
\hline Asthma & 50 & $9 \%$ & & & 67 & $12 \%$ & & & 0.10 & \\
\hline Back Pain & 189 & $33 \%$ & & & 228 & $40 \%$ & & & 0.02 & 0.01 \\
\hline Cancer now or in the past & 18 & $3 \%$ & & & 24 & $4 \%$ & & & 0.35 & \\
\hline Depression & 131 & $23 \%$ & & & 130 & $23 \%$ & & & 0.92 & \\
\hline Diabetes & 20 & $4 \%$ & & & 71 & $13 \%$ & & & $<0.0005$ & 0.03 \\
\hline Heart Disease & 11 & $2 \%$ & & & 14 & $3 \%$ & & & 0.50 & \\
\hline High Blood Pressure & 53 & $9 \%$ & & & 114 & $20 \%$ & & & $<0.0005$ & 0.02 \\
\hline Insomnia & 117 & $21 \%$ & & & 98 & $17 \%$ & & & 0.15 & \\
\hline
\end{tabular}


Table 1 (continued)

\begin{tabular}{|c|c|c|c|c|c|c|c|c|c|c|}
\hline \multirow[t]{2}{*}{ Variable } & \multicolumn{4}{|c|}{ DMD caregivers $(n=566)$} & \multicolumn{4}{|c|}{ Comparison caregivers $(n=594)$} & \multirow{2}{*}{$\begin{array}{l}p \text { from } T \text { - or } \\
\text { chi-square } \\
\text { test }\end{array}$} & \multirow{2}{*}{$\begin{array}{l}\text { Variance } \\
\text { explained If } p \\
<.05\end{array}$} \\
\hline & Mean & SD & Min & Max & Mean & SD & Min & Max & & \\
\hline Kidney Disease & 3 & $1 \%$ & & & 7 & $1 \%$ & & & 0.23 & \\
\hline Liver Disease & 5 & $1 \%$ & & & 3 & $1 \%$ & & & 0.44 & \\
\hline Lung Disease & 3 & $1 \%$ & & & 6 & $1 \%$ & & & 0.35 & \\
\hline Stroke & 3 & $1 \%$ & & & 9 & $2 \%$ & & & 0.10 & \\
\hline Ulcer or Stomach Disease & 18 & $3 \%$ & & & 20 & $4 \%$ & & & 0.74 & \\
\hline \multirow[t]{2}{*}{ Other } & 66 & $12 \%$ & & & 55 & $10 \%$ & & & 0.30 & \\
\hline & Mean & SD & Min & Max & Mean & SD & Min & Max & & \\
\hline BMI & 26.9 & 6.0 & 16.5 & 40.0 & 27.1 & 5.8 & 15 & 40 & 0.49 & \\
\hline Smoking Status & Frequency & $\%$ & & & Frequency & $\%$ & & & $<0.0005$ & 0.07 \\
\hline Never Smoked & 447 & $79 \%$ & & & 337 & $57 \%$ & & & & \\
\hline Used to Smoke & 58 & $10 \%$ & & & 68 & $11 \%$ & & & & \\
\hline Some Days Currently & 23 & $4 \%$ & & & 70 & $12 \%$ & & & & \\
\hline Every Day Currently & 35 & $6 \%$ & & & 116 & $20 \%$ & & & & \\
\hline Missing & 3 & $1 \%$ & & & 3 & $1 \%$ & & & & \\
\hline Work Status & & & & & & & & & $<0.0005$ & 0.07 \\
\hline Employed & 323 & $57 \%$ & & & 432 & $73 \%$ & & & & \\
\hline Unemployed & 202 & $36 \%$ & & & 91 & $15 \%$ & & & & \\
\hline Retired & 10 & $2 \%$ & & & 40 & $7 \%$ & & & & \\
\hline Disabled due to medical condition & 10 & $2 \%$ & & & 20 & $3 \%$ & & & & \\
\hline Missing & 21 & $4 \%$ & & & 11 & $2 \%$ & & & & \\
\hline Hours Worked per Week & & & & & & & & & $<0.0005$ & 0.04 \\
\hline Does not apply & 242 & $43 \%$ & & & 162 & $27 \%$ & & & & \\
\hline$<20$ & 15 & $3 \%$ & & & 12 & $2 \%$ & & & & \\
\hline $20-29$ & 41 & $7 \%$ & & & 33 & $6 \%$ & & & & \\
\hline $30-39$ & 75 & $13 \%$ & & & 139 & $23 \%$ & & & & \\
\hline $40+$ & 193 & $34 \%$ & & & 248 & $42 \%$ & & & & \\
\hline \multicolumn{11}{|l|}{ COVID-Specific Variables } \\
\hline Whether anyone in household infected (\%) & & & & & & & & & $<0.0005$ & 0.04 \\
\hline Definitely no & 489 & $86 \%$ & & & 440 & $74 \%$ & & & & \\
\hline Probably no & 58 & $10 \%$ & & & 79 & $13 \%$ & & & & \\
\hline Probably yes & 8 & $1 \%$ & & & 29 & $5 \%$ & & & & \\
\hline \multirow[t]{2}{*}{ Definitely yes } & 3 & $1 \%$ & & & 33 & $6 \%$ & & & & \\
\hline & Mean & SD & Min & Max & Mean & SD & Min & Max & & \\
\hline Financial hardship & 18.8 & 9.0 & 6 & 42 & 21.4 & 7.2 & 6 & 42 & $<0.0005$ & 0.02 \\
\hline Isolation & 14.1 & 6.5 & 4 & 28 & 14.3 & 5.8 & 4 & 28 & 0.68 & \\
\hline Social support & 16 & 4.9 & 0 & 23 & 16.5 & 5.2 & 0 & 23 & 0.15 & \\
\hline Continuity of healthcare & 2.6 & 0.7 & 0 & 3 & 2.5 & 0.8 & 0 & 3 & 0.09 & \\
\hline
\end{tabular}

*A non-response was counted as the absence of the comorbidity in question

propensity scores were largely driven by Group differences in caregiver age, gender, race, and smoking/vaping status (see Additional file 1: Table S1 for details).

\section{Care recipient characteristics}

Table 2 describes the care-recipient characteristics and, where relevant, a contrast of the DMD and comparison caregiver samples, again along with p-values from t-tests or chi-squared tests and explained variance for statistically significant differences. Care recipients for the comparison caregiver sample would be their own children. DMD caregivers reported providing support for one to five people with DMD (mean $=1.1, \mathrm{SD}=0.4$ ), of whom up to three were their own children (Table 2). Ninety-seven percent of these caregivers were parents of the DMD index person (Table 2). An average of two people other than the caregiver were living in the household and providing support to the person(s) with DMD. The 


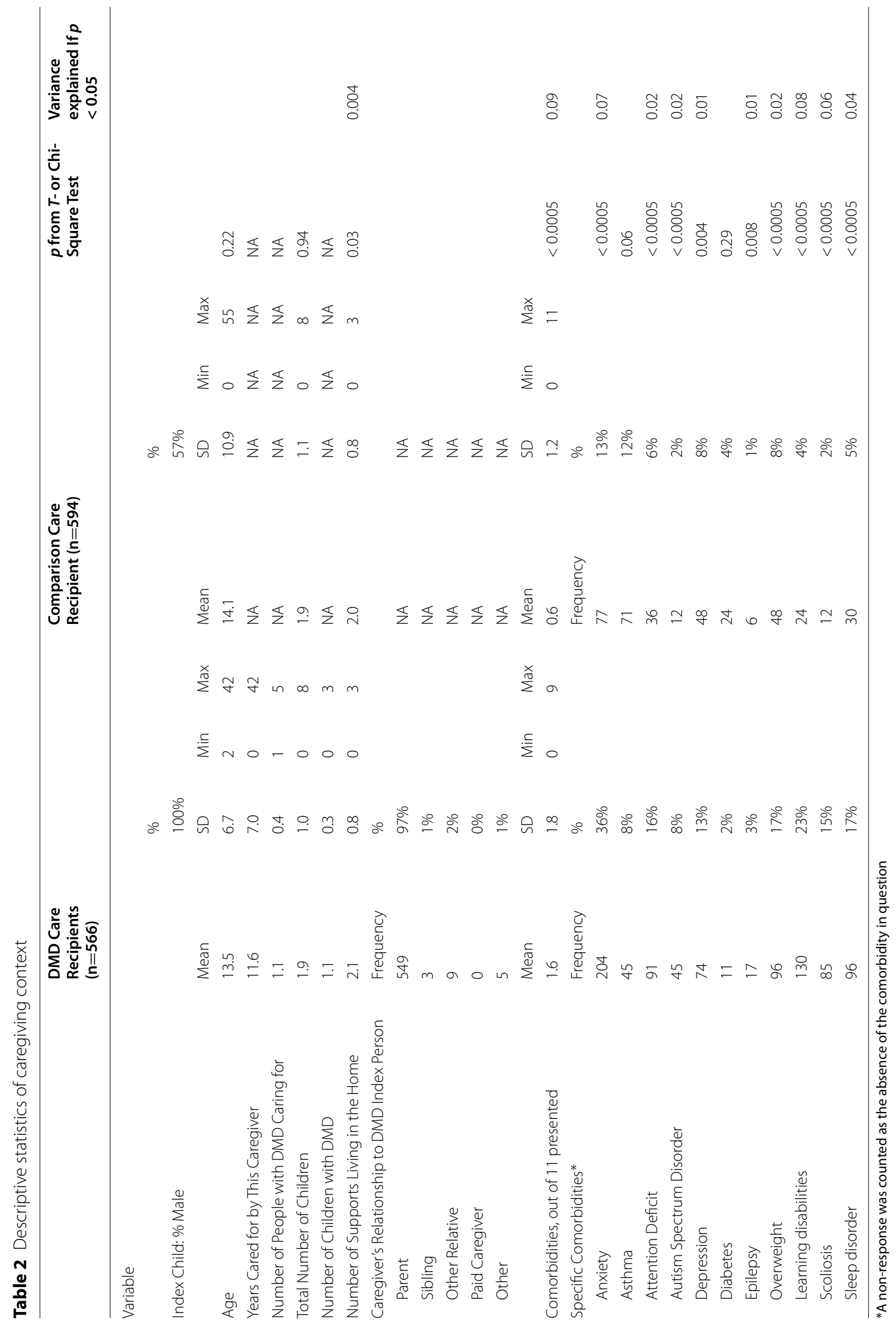


index DMD child had a mean age of 13.5 and an average of 1.6 comorbidities out of 15 presented, the most prevalent of which were anxiety, learning disabilities, attention deficit, sleep disorder, being overweight, scoliosis, and depression. The DMD care recipients were generally more likely to have each of the listed comorbidities than the comparison group with the exception of no differences on the prevalence of asthma and diabetes.

\section{Unique aspects of DMD caregiving Caregiver impact}

Figure 1 shows box-and-whiskers plots of the eight DCI subscales by DMD Child Age Group, and Additional file 3: Table $\mathrm{S} 2$ shows the descriptive statistics of the subscales. An analysis of variance model revealed statistically significant differences by Child Age Group in Emotional Impact (6\% explained variance), Symptom and Physical Impact (5\% in both), and Lifestyle, Social, and Financial Impact (each 3\%) (Additional file 3: Table S2). We found upward trends as the age of the index child increased through age 13-17, in all domains except Practical Impact and Positive Emotions.

\section{Home and vehicle accommodations}

Table 3 provides information about the types of accommodations reported by DMD caregivers to make their home or vehicle more accessible for their child with DMD. The most prevalent were modifying their home entrance (67\%), bathroom (53\%), or inside-home doorways (49\%); purchasing a handicap-accessible van (45\%); and modifying a bedroom (43\%). About a quarter of parents modified the kitchen and $14 \%$ installed an elevator. Figure 2 shows the greater frequency for home accommodations for older children.

\section{Impact on siblings}

Table 3 also provides information on the impact of DMD on the index child's siblings. In addition to having to help with DMD caregiving, many siblings gave up time with friends (59\% slightly, moderately, or strongly agreed), sports or extracurricular activities (52\%), and/or summer camp or travel (44\%). Also, a fair number of DMD caregivers (52\%) reported that there was insufficient finances for siblings' activities or schooling. On the other hand, participants tended to disagree that, due to DMD in the family, siblings had lost other opportunities, chosen only colleges close to home, or given up on going to college.

\section{Caregiver group differences on outcomes}

Table 3 provides the descriptive statistics and unadjusted comparisons on outcomes. Table 4 and

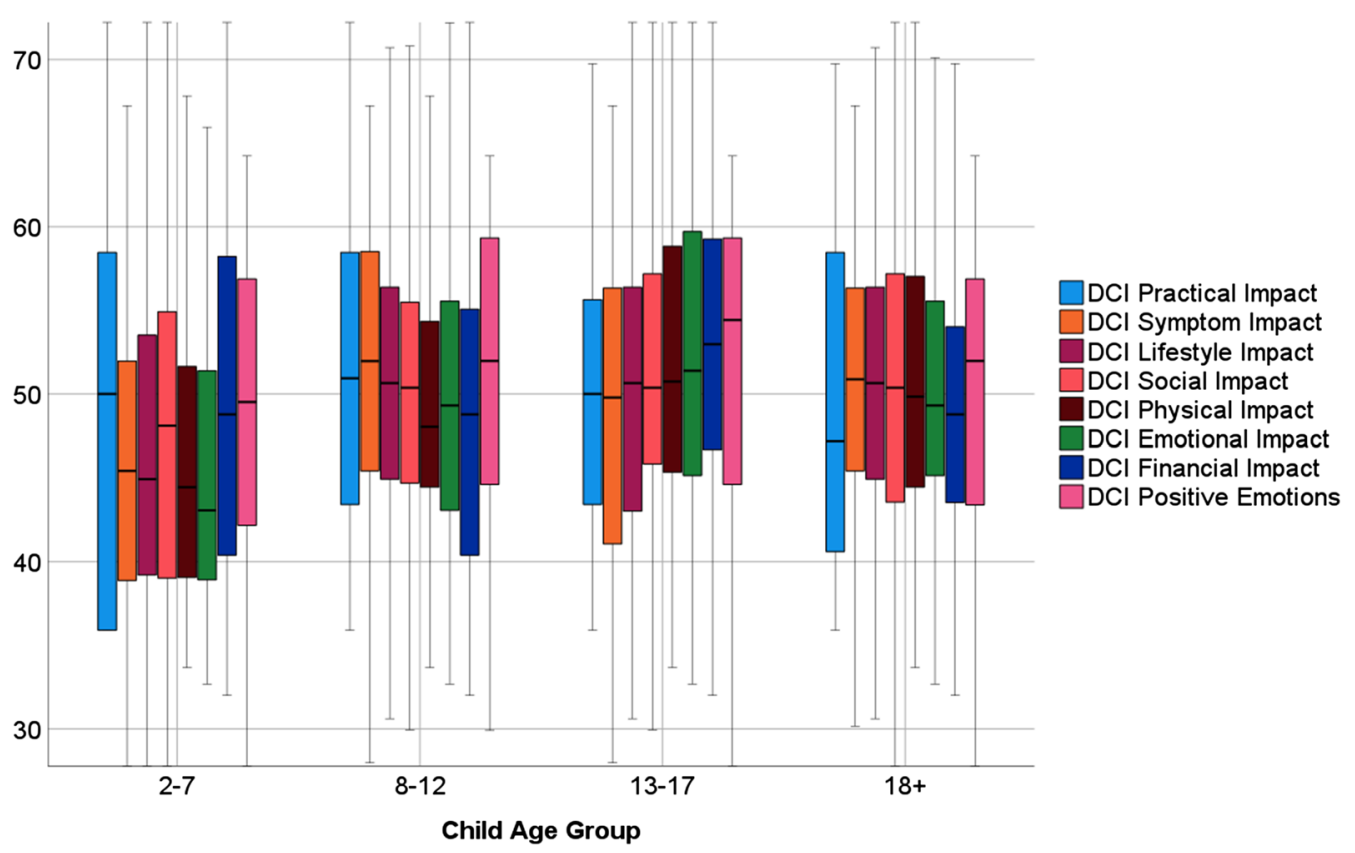

Fig. 1 DMD Caregiver Impact (DCI) subscale scores by Child Age Group. These box-and-whiskers plots show the distributions of the eight DCl subscale scores by DMD Child Age Group strata. There were upward trends as the age of the index child increased through age 13-17, in all domains except Practical Impact and Positive Emotions 


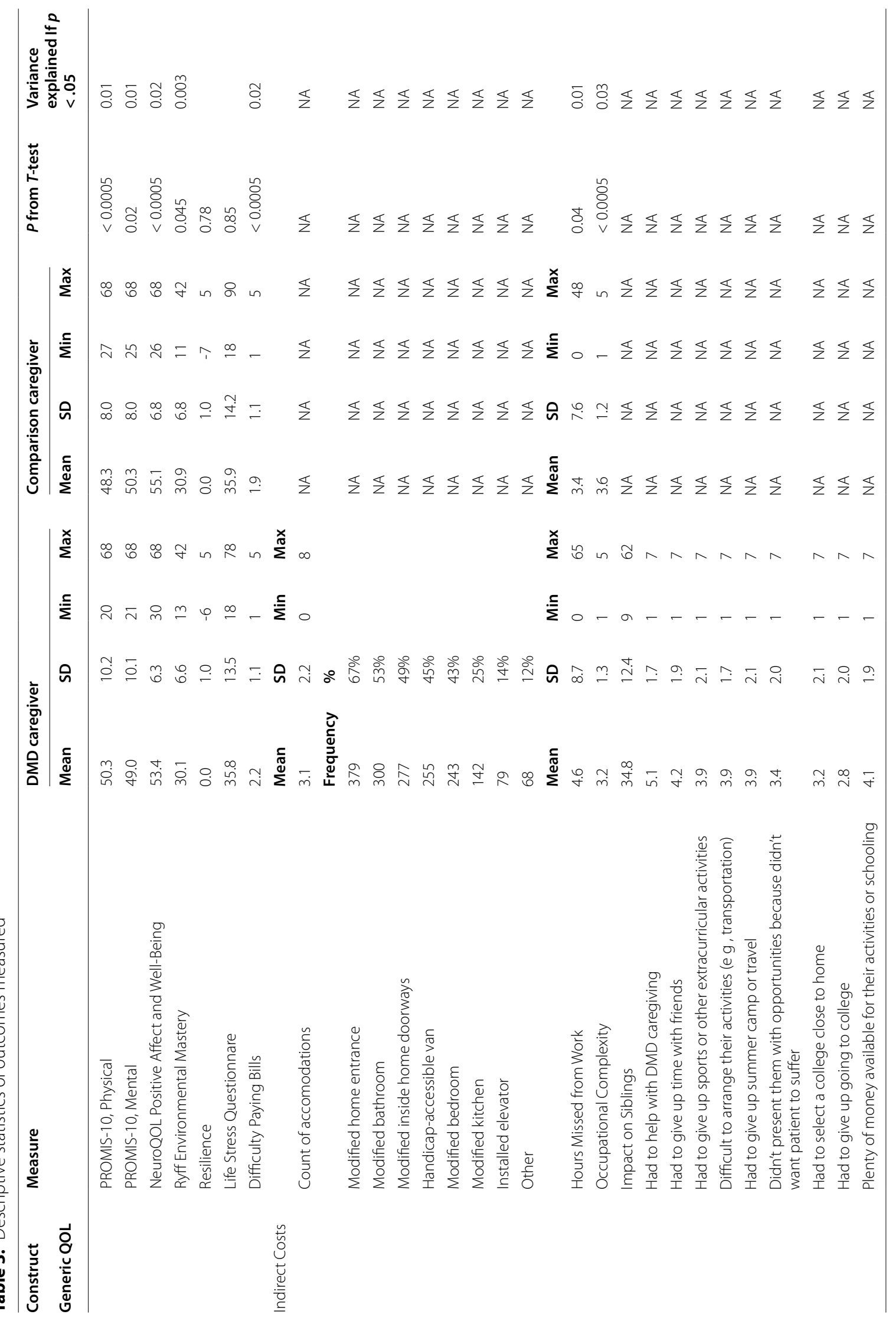




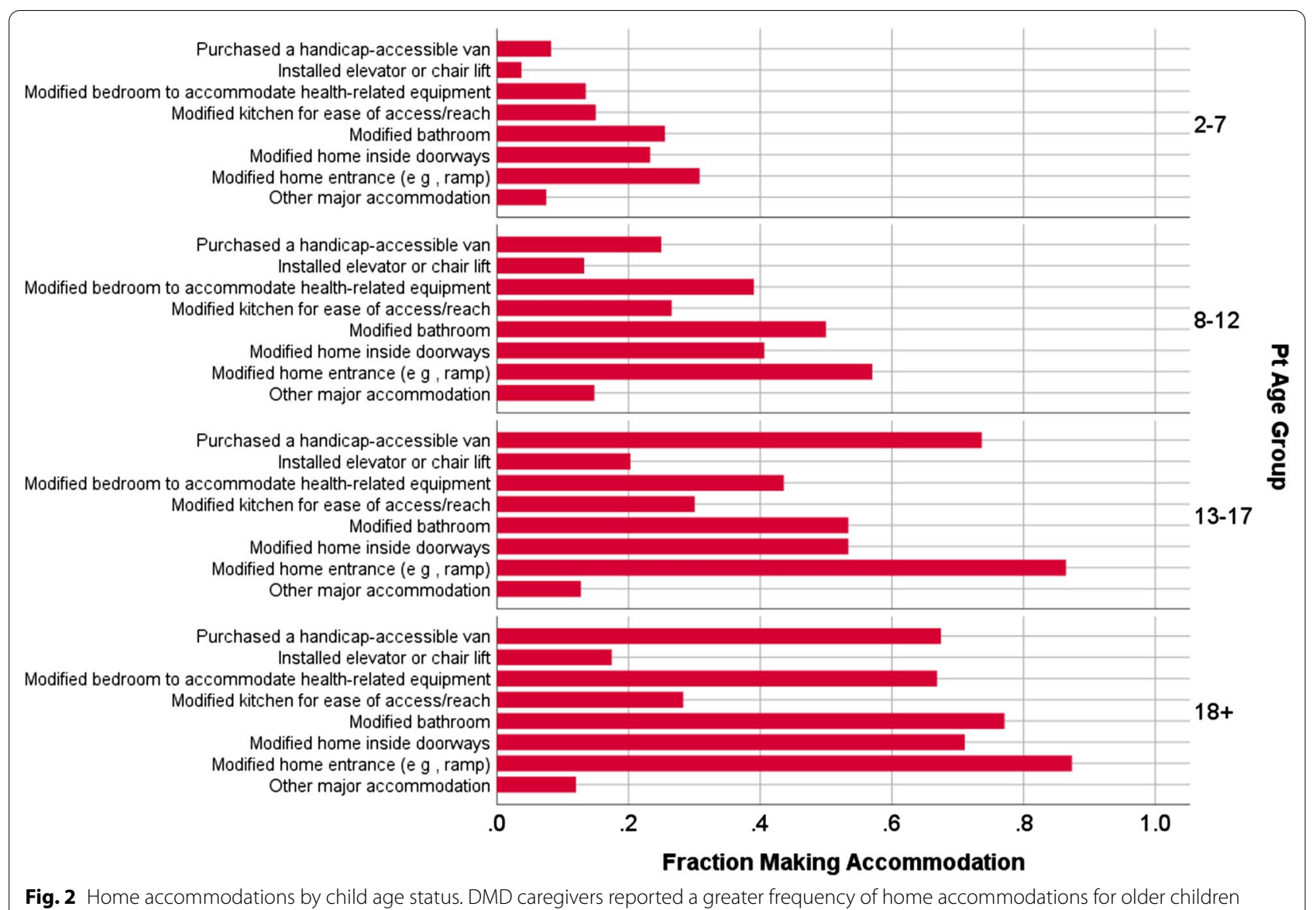

Additional file 3: Table S3 show results of the general linear models that assessed Group differences after adjusting for propensity score. The DMD Caregivers reported better physical health but worse mental health, positive affect/well-being, environmental mastery, and difficulty paying bills (explained variance $0.5 \%, 0.4 \%, 1.3 \%, 0.4 \%$, and $2.5 \%$, respectively; two of these met Cohen's [60] criterion for "small" effect size; Table 3). There were no Group differences on resilience or life stress in these covariate-adjusted models.

A separate set of models examined the differential impact of Child Age Group on outcomes via interactions between caregiver group ("Group") and Child Age Group. These models showed that, compared

Table 4. Group effects from general linear models adjusted for propensity scores

\begin{tabular}{|c|c|c|c|c|c|c|c|}
\hline \multirow[t]{2}{*}{ Dependent variable } & \multirow{2}{*}{$\begin{array}{l}\text { b for DMD } \\
\text { caregiver }\end{array}$} & \multirow[t]{2}{*}{ Std. error } & \multirow[t]{2}{*}{$t$} & \multirow[t]{2}{*}{$p$} & \multicolumn{2}{|c|}{$95 \%$ confidence interval } & \multirow{2}{*}{$\begin{array}{l}\text { Partial Eta } \\
\text { squared }\end{array}$} \\
\hline & & & & & Lower bound & Upper bound & \\
\hline PROMIS physical & 1.45 & 0.58 & 2.47 & 0.01 & 0.30 & 2.60 & 0.005 \\
\hline PROMIS mental & -1.26 & 0.58 & -2.17 & 0.03 & -2.41 & -0.12 & 0.004 \\
\hline NeuroQOL positive affect \& well-being & -1.61 & 0.42 & -3.86 & 0.00 & -2.43 & -0.79 & 0.013 \\
\hline Ryff environmental mastery & -0.92 & 0.43 & -2.15 & 0.03 & -1.76 & -0.08 & 0.004 \\
\hline Resilience & -0.10 & 0.06 & -1.54 & 0.12 & -0.22 & 0.03 & 0.002 \\
\hline Stress & 1.14 & 0.88 & 1.29 & 0.20 & -0.59 & 2.87 & 0.001 \\
\hline Difficulty paying bills & 0.39 & 0.07 & 5.41 & 0.00 & 0.25 & 0.53 & 0.025 \\
\hline Hours missed from work* & 1.68 & 0.63 & 2.68 & 0.01 & 0.45 & 2.91 & 0.009 \\
\hline
\end{tabular}

*Excludes those not working 
to controls and after adjusting for propensity scores, DMD caregivers reported worse physical health, mental health, positive affect, environmental mastery, stressful life events, and difficulty paying bills than comparison caregivers. DMD caregivers reported worse outcomes if their DMD child was in certain age groups, with the outcomes and corresponding age groups as follows: physical health (age 13+); mental health (age 13-17); positive affect (age 18+); environmental mastery (age $8+$ ); stress (age $13+$ ); and difficulty paying bills (age 13+) (Table 5 and Additional file 4: Table S4).

\section{Caregiver group differences on work productivity}

A general linear model adjusting for propensity score suggested that employed DMD caregivers missed more hours from work than comparison caregivers (explained variance $0.9 \%$; Table 4 ). A separate model revealed no differential effect by Child Age Group (Table 5).

\section{Caregiver group differences on unrealized ambitions}

DMD parents were much more likely than comparison parents to have a technical degree, some college, or a 2 -year college degree ( $44 \%$ vs. $26 \%$ of the samples, respectively). DMD caregivers were less likely to have a graduate-level education (10\% versus $34 \%$ of the samples respectively; Table 1). Explained variance for education was high at $11 \%$. Moreover, of the two groups, DMD caregivers showed levels of occupational complexity that, after adjusting for propensity score and education, were on average 0.15 points lower on a 1-5 scale. This was essentially true at all levels except graduate-level training (Fig. 3). These findings were similar in models including and excluding caregivers without work history. In the latter model, missing values of O*NET were imputed as "2", reflecting being a caregiver, for 139 and 56 in DMD caregiver and comparison groups, respectively. There was no link between Child Age Group and occupational complexity. Further, of the two groups, the DMD caregivers under-achieved with respect to community education norms, as measured by ZIP-code educational averages $(0.8 \%$ explained variance), after controlling for propensity score.

\section{Discussion}

The present work revealed that DMD caregivers appear to fare worse on most outcomes than a nationally representative comparison group, even after adjusting for possible confounders. Upon further inspection, it became clear that providing caregiving support for DMD teenage children was the most challenging. This is a difficult age for any parent, but boys with DMD are also becoming increasingly dependent upon a wheelchair for mobility, giving rise to increased intensity of care and physical demands on caregivers. While DMD caregivers seemed to have better physical health in simpler models, more complex models that considered the child's age group showed a greater toll taken on DMD caregivers of adult and especially teenage children. We found no Group difference in main effects of resilience or stress, but further analysis revealed a greater strain for the latter outcome when caring for children with DMD who were teenage or older (interactions). The policy implications of these findings are that considering the caregiver impact would be highly relevant to determining the value and costeffectiveness of DMD therapies. Effective treatment is associated with lower caregiver impact in advanced Parkinson's disease, for example [61]. In addition to QOL challenges, DMD caregivers seemed to have restricted their professional ambitions. They were less likely than the comparison caregivers to work or work full-time, and more likely to miss time from work. They were much less likely to complete a college degree and less likely to achieve educationally what would be expected from community norms. Even among those with a college education, DMD caregivers achieved less complex occupations than controls. Further, many DMD caregivers reported that their other children had given up time with friends, sports, extracurricular activities, and/or summer camp or travel due to the index child's DMD. These differences suggest constraints on life choices, and presence of hidden restrictions due to DMD caregiving. All of these hidden and not-so-hidden restrictions could be mitigated by effective treatment. Future research might, for example, investigate whether a DMD treatment is associated with better QOL outcomes in the short term, and higher educational or occupational achievement in the long term.

The comparability in resilience between the two groups is noteworthy given the extensive difficulties faced by DMD caregivers. In addition to the many costly accommodations they had to make as the child's DMD progressed, caregivers reported a general worsening on many aspects of the DCI. Nonetheless, DMD caregivers' DCI Positive Emotions scores were consistent across child age groups despite older children's greater caregiving impact indicated by the other domain scores. Managing to maintain engagement and positivity in the face of DMD adversities speaks to an inner strength and grit worthy of further investigation. It may also signal response-shift effects [62], referring to changes in internal standards, values and/or conceptualization of quality of life, all of which can also be investigated in future longitudinal research.

Resilience in maintaining responsibilities in the face of DMD caregiving may relate to better self-care. DMD 
Table 5. Group and Child Age Main- and Interaction-Effects from General Linear Models Adjusted for Propensity Scores

\begin{tabular}{|c|c|c|c|c|c|c|c|c|}
\hline \multirow[t]{2}{*}{ Dependent variable } & \multirow[t]{2}{*}{ Parameter } & \multirow[t]{2}{*}{ b } & \multirow[t]{2}{*}{ Std. error } & \multirow[t]{2}{*}{$t$} & \multirow[t]{2}{*}{$p$} & \multicolumn{2}{|c|}{ 95\% Confidence interval } & \multirow{2}{*}{$\begin{array}{l}\text { Partial eta } \\
\text { squared }\end{array}$} \\
\hline & & & & & & Lower bound & Upper bound & \\
\hline \multirow[t]{7}{*}{ PROMIS physical } & Child Age 18+ & 0.33 & 1.07 & 0.31 & 0.76 & -1.78 & 2.43 & 0.000 \\
\hline & Child Age 13-17 & 1.20 & 1.09 & 1.10 & 0.27 & -0.94 & 3.34 & 0.001 \\
\hline & Child Age 8-12 & -0.89 & 1.00 & -0.89 & 0.37 & -2.85 & 1.06 & 0.001 \\
\hline & DMD Caregiver & 6.00 & 1.07 & 5.60 & 0.00 & 3.90 & 8.10 & 0.027 \\
\hline & DMD Caregiver * Child Age 18+ & -6.45 & 1.48 & -4.34 & 0.00 & -9.36 & -3.53 & 0.017 \\
\hline & $\begin{array}{l}\text { DMD Caregiver * Child Age } \\
13-17\end{array}$ & -9.00 & 1.55 & -5.81 & 0.00 & -12.04 & -5.96 & 0.029 \\
\hline & DMD Caregiver * Child Age 8-12 & -2.08 & 1.49 & -1.40 & 0.16 & -4.99 & 0.84 & 0.002 \\
\hline \multirow[t]{7}{*}{ PROMIS mental } & Child Age 18+ & 0.49 & 1.08 & 0.45 & 0.65 & -1.63 & 2.61 & 0.000 \\
\hline & Child Age 13-17 & 2.76 & 1.10 & 2.51 & 0.01 & 0.60 & 4.92 & 0.006 \\
\hline & Child Age 8-12 & 0.64 & 1.01 & 0.63 & 0.53 & -1.34 & 2.61 & 0.000 \\
\hline & DMD Caregiver & 3.14 & 1.08 & 2.90 & 0.00 & 1.02 & 5.26 & 0.008 \\
\hline & DMD Caregiver * Child Age 18+ & -4.49 & 1.50 & -3.00 & 0.00 & -7.43 & -1.55 & 0.008 \\
\hline & $\begin{array}{l}\text { DMD Caregiver * Child Age } \\
13-17\end{array}$ & -8.99 & 1.56 & -5.76 & 0.00 & -12.05 & -5.93 & 0.029 \\
\hline & DMD Caregiver * Child Age 8-12 & -4.22 & 1.50 & -2.81 & 0.00 & -7.16 & -1.28 & 0.007 \\
\hline \multirow{7}{*}{$\begin{array}{l}\text { NeuroQOL positive affect and } \\
\text { well being }\end{array}$} & Child Age 18+ & 0.50 & 0.78 & 0.64 & 0.52 & -1.03 & 2.04 & 0.000 \\
\hline & Child age $13-17$ & 0.65 & 0.80 & 0.82 & 0.41 & -0.91 & 2.22 & 0.001 \\
\hline & Child age 8-12 & 0.76 & 0.73 & 1.04 & 0.30 & -0.67 & 2.19 & 0.001 \\
\hline & DMD caregiver & -0.49 & 0.78 & -0.63 & 0.53 & -2.03 & 1.04 & 0.000 \\
\hline & DMD caregiver ${ }^{*}$ Child age $18+$ & -2.41 & 1.08 & -2.22 & 0.03 & -4.54 & -0.28 & 0.004 \\
\hline & DMD caregiver * Child age $13-17$ & -1.46 & 1.13 & -1.29 & 0.20 & -3.68 & 0.76 & 0.001 \\
\hline & DMD caregiver * Child age 8-12 & -0.15 & 1.09 & -0.14 & 0.89 & -2.28 & 1.98 & 0.000 \\
\hline \multirow[t]{7}{*}{ Ryff environmental mastery } & Child age 18+ & 2.79 & 0.79 & 3.53 & 0.00 & 1.24 & 4.34 & 0.011 \\
\hline & Child age 13-17 & 1.89 & 0.81 & 2.34 & 0.02 & 0.30 & 3.47 & 0.005 \\
\hline & Child age 8-12 & 0.85 & 0.74 & 1.15 & 0.25 & -0.60 & 2.29 & 0.001 \\
\hline & DMD caregiver & 2.68 & 0.79 & 3.38 & 0.00 & 1.13 & 4.23 & 0.010 \\
\hline & DMD caregiver * Child age $18+$ & -5.46 & 1.10 & -4.98 & 0.00 & -7.62 & -3.31 & 0.022 \\
\hline & DMD caregiver * Child age $13-17$ & -6.11 & 1.14 & -5.34 & 0.00 & -8.36 & -3.87 & 0.025 \\
\hline & DMD caregiver * Child age 8-12 & -3.36 & 1.10 & -3.06 & 0.00 & -5.51 & -1.21 & 0.008 \\
\hline \multirow[t]{7}{*}{ Resilience } & Child age $18+$ & 0.01 & 0.12 & 0.07 & 0.94 & -0.22 & 0.24 & 0.000 \\
\hline & Child age 13-17 & 0.07 & 0.12 & 0.57 & 0.57 & -0.17 & 0.31 & 0.000 \\
\hline & Child Age 8-12 & 0.03 & 0.11 & 0.25 & 0.80 & -0.19 & 0.24 & 0.000 \\
\hline & DMD Caregiver & -0.07 & 0.12 & -0.57 & 0.57 & -0.30 & 0.17 & 0.000 \\
\hline & DMD Caregiver ${ }^{*}$ Child Age $18+$ & 0.11 & 0.16 & 0.66 & 0.51 & -0.21 & 0.43 & 0.000 \\
\hline & $\begin{array}{l}\text { DMD Caregiver * Child Age } \\
13-17\end{array}$ & -0.30 & 0.17 & -1.75 & 0.08 & -0.64 & 0.04 & 0.003 \\
\hline & DMD Caregiver * Child Age 8-12 & 0.00 & 0.16 & 0.00 & 1.00 & -0.32 & 0.32 & 0.000 \\
\hline \multirow[t]{7}{*}{ Stress } & Child Age 18+ & -7.51 & 1.61 & -4.65 & 0.00 & -10.68 & -4.35 & 0.019 \\
\hline & Child Age 13-17 & -5.64 & 1.64 & -3.43 & 0.00 & -8.86 & -2.41 & 0.010 \\
\hline & Child Age 8-12 & -1.16 & 1.50 & -0.77 & 0.44 & -4.11 & 1.79 & 0.001 \\
\hline & DMD Caregiver & -5.70 & 1.61 & -3.53 & 0.00 & -8.87 & -2.53 & 0.011 \\
\hline & DMD Caregiver * Child Age 18+ & 10.58 & 2.24 & 4.73 & 0.00 & 6.19 & 14.96 & 0.020 \\
\hline & $\begin{array}{l}\text { DMD Caregiver * Child Age } \\
13-17\end{array}$ & 15.60 & 2.33 & 6.69 & 0.00 & 11.02 & 20.17 & 0.039 \\
\hline & DMD Caregiver * Child Age 8-12 & 3.90 & 2.24 & 1.74 & 0.08 & -0.50 & 8.29 & 0.003 \\
\hline \multirow[t]{2}{*}{ Difficulty Paying Bills } & Child Age 18+ & -0.40 & 0.13 & -3.00 & 0.00 & -0.66 & -0.14 & 0.008 \\
\hline & Child Age 13-17 & -0.30 & 0.14 & -2.17 & 0.03 & -0.56 & -0.03 & 0.004 \\
\hline
\end{tabular}


Table 5. (continued)

\begin{tabular}{|c|c|c|c|c|c|c|c|c|}
\hline \multirow[t]{2}{*}{ Dependent variable } & \multirow[t]{2}{*}{ Parameter } & \multirow[t]{2}{*}{ b } & \multirow[t]{2}{*}{ Std. error } & \multirow[t]{2}{*}{$t$} & \multirow[t]{2}{*}{$p$} & \multicolumn{2}{|c|}{ 95\% Confidence interval } & \multirow{2}{*}{$\begin{array}{l}\text { Partial eta } \\
\text { squared }\end{array}$} \\
\hline & & & & & & Lower bound & Upper bound & \\
\hline & Child Age 8-12 & -0.06 & 0.12 & -0.49 & 0.63 & -0.30 & 0.18 & 0.000 \\
\hline & DMD Caregiver & 0.02 & 0.13 & 0.11 & 0.91 & -0.25 & 0.28 & 0.000 \\
\hline & DMD Caregiver * Child Age $18+$ & 0.53 & 0.19 & 2.84 & 0.00 & 0.16 & 0.89 & 0.007 \\
\hline & $\begin{array}{l}\text { DMD Caregiver * Child Age } \\
13-17\end{array}$ & 0.88 & 0.19 & 4.56 & 0.00 & 0.50 & 1.26 & 0.018 \\
\hline & DMD Caregiver * Child Age 8-12 & 0.26 & 0.19 & 1.39 & 0.17 & -0.11 & 0.62 & 0.002 \\
\hline \multirow[t]{7}{*}{ Hours Missed from Work* } & Child Age 18+ & -2.16 & 1.20 & -1.80 & 0.07 & -4.51 & 0.19 & 0.004 \\
\hline & Child Age 13-17 & -1.03 & 1.09 & -0.95 & 0.34 & -3.17 & 1.10 & 0.001 \\
\hline & Child Age 8-12 & -0.42 & 1.00 & -0.42 & 0.68 & -2.38 & 1.55 & 0.000 \\
\hline & DMD Caregiver & 3.28 & 1.13 & 2.90 & 0.00 & 1.06 & 5.50 & 0.011 \\
\hline & DMD Caregiver * Child Age 18+ & -0.77 & 1.65 & -0.47 & 0.64 & -4.01 & 2.47 & 0.000 \\
\hline & $\begin{array}{l}\text { DMD Caregiver * Child Age } \\
13-17\end{array}$ & -2.37 & 1.76 & -1.35 & 0.18 & -5.83 & 1.08 & 0.002 \\
\hline & DMD Caregiver * Child Age 8-12 & -2.25 & 1.62 & -1.39 & 0.17 & -5.43 & 0.93 & 0.003 \\
\hline
\end{tabular}

*Excludes those not working

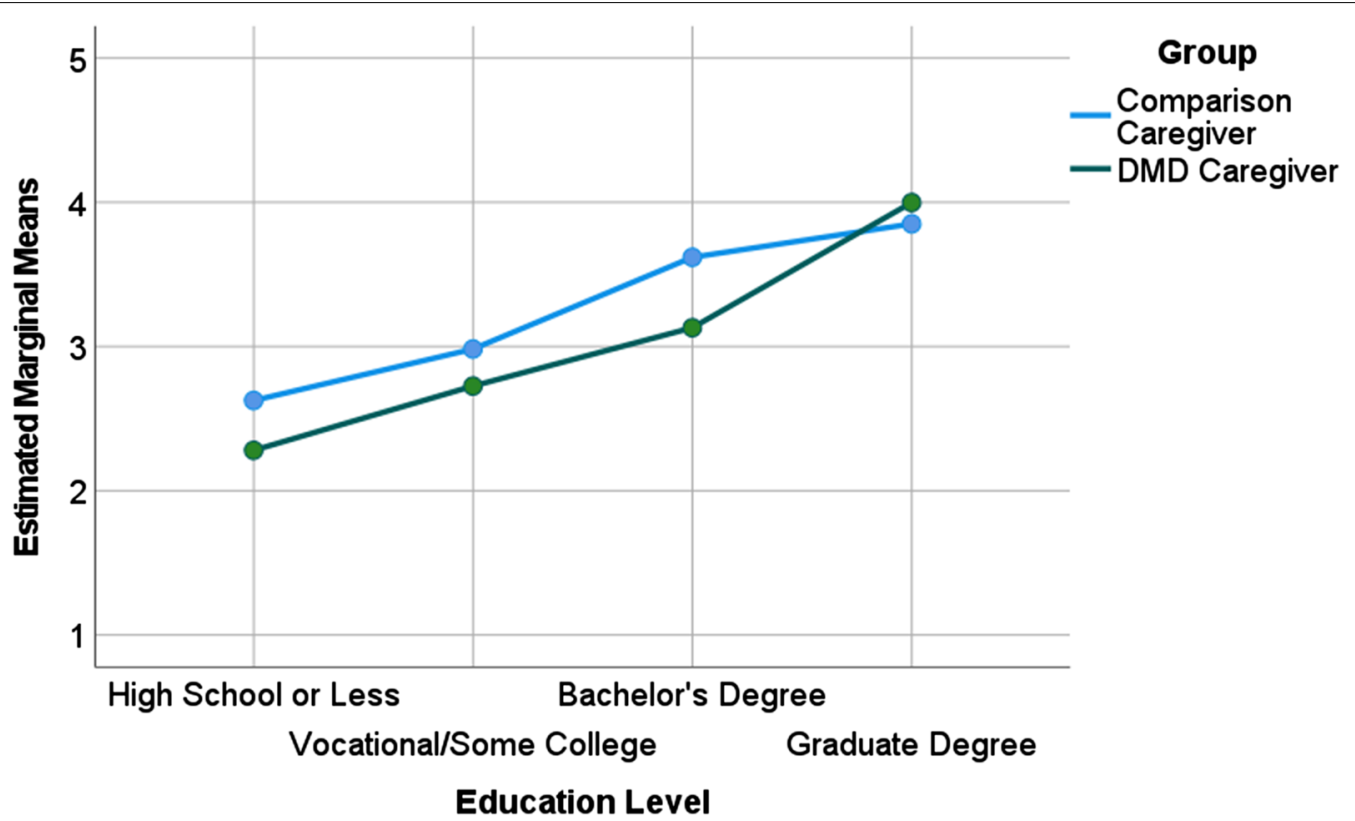

Fig. 3 Occupational Complexity achieved by DMD versus comparison caregivers. DMD caregivers showed lower levels of occupational complexity after adjusting for education, across all levels with the exception of graduate-level training

caregivers were less likely to smoke or vape than comparison caregivers (never smoked: $79 \%$ vs. $57 \%$ ), and had avoided COVID-19 infection better than the comparison group had (probably or definitely no infection: $96 \%$ vs. 87\%). DMD Caregivers also suffered less financial hardship than comparison caregivers, which could be partially due to a greater proportion of them being unemployed to begin with, so Covid-19 did not appreciably change their financial circumstances. This finding is consistent with past research that documented lower perceived impact among those caregivers who practice more health-promoting behaviors [63]. Future research might address whether DMD caregivers are more likely to engage in reserve-building activities that stimulate the brain and lead to greater flexibility and more adaptive ways of coping [64-69]. 
The present study has distinct advantages over past research cited in our Introduction in its ample sample size, inclusion of a nationally representative comparison group, coverage of age-related subgroups, and measurement of diverse yet relevant constructs. The majority of prior literature has not characterized the demands placed upon parent-caregivers over time. The present study described the trajectory of caregiving over time and across different stages of the disease, likely reflecting the increasing complexity and scope of caregiver responsibilities as people with DMD progress through the disease.

The limitations of the present work must, however, be acknowledged. Because of the snowball sampling employed, it is not possible to calculate a response rate or to assess selection biases. Second and similar to much caregiver research, the DMD caregivers are disproportionately female, whereas the comparison group is more balanced. Third, the study sample does not include enough Hispanic, Black, Asian-American, or Native American participants to enable subgroup analyses. Future research might address caregiver impact in these important cohorts. Fourth, in order to include all caregivers in the occupational complexity analysis, we replaced each missing value with a "2", reflecting published benchmarks for "caregiver." This imputation yielded greater power but, as it was applied disproportionately to DMD caregivers, it may have led to an underestimate of their occupational complexity. Fifth, educational differences between the caregiver samples may have pre-dated the arrival of their children, so it is unclear whether these differences are a direct effect of differences in caregiving demands. Sixth, this case-control study has limitations due to its quasi-experimental design. One cannot randomize individuals to be caregivers of people with DMD, so causal inference is difficult. Nonetheless, the inclusion of a general-population comparison cohort facilitates some confidence in the study's conclusions. Seventh, the mean age of the DMD cohort was 13.5 years, so it is possible that the findings are skewed to an older cohort. Those with younger children (i.e., who were more recently diagnosed) may have differing impacts. Nonetheless, this study serves to highlight that even after many years of diagnosis with DMD, parent-caregivers do continue to struggle, perhaps as a product of the progressive nature of the illness. Finally, the outcome differences noted, including those related to child age, are based on cross-sectional data. A longitudinal assessment could address whether such differences persist within families.

In summary, DMD has a high and broad impact, not only on the patients who suffer from this disease but also on their caregivers. DMD caregivers fared worse on most QOL outcomes and faced more hurdles in their educational and work life. The severity of DMD was associated with caregiver impact, and caring for teenagers with DMD was particularly challenging have greater impact. Findings from this study suggest that DMD caregivers face numerous constraints and indirect costs that impact their health, well-being, and financial welfare. Nonetheless, parents of DMD children of all ages maintained notable resilience and positivity.

\section{Abbreviations \\ DMD: Duchenne muscular dystrophy; LLC: Limited liability corporation; HRQOL: Health-related quality of life; QOL: Quality of life.}

\section{Supplementary Information}

The online version contains supplementary material available at https://doi. org/10.1186/s41687-021-00386-y.

Additional file 1. Supplemental Table 1. Propensity Score Model. Additional file 2. Supplemental Table 2. DMD Caregiver Impact Descriptive Statistics and ANOVA results.

Additional file 3. Supplemental Table 3. Full Output of General Linear Models Evaluating Group Effects adjusted for propensity scores.

Additional file 4. Supplemental Table 4. Group and Child Age Mainand Interaction-Effects from General Linear Models Adjusted for Propensity Scores.

Additional file 5. Supplemental Figure 1. Bar chart showing numbers of DMD and comparison caregivers in the four Child Age Group strata.

\section{Acknowledgments}

We are grateful to Eli Biletch and Richard Stuart for help with data management, and to the participants themselves who provided interview and survey data for this project and helped to recruit DMD caregivers.

\section{Authors' contributions}

CES, KG and IA designed the research study. CES and RBS implemented the study and analyses. CES and RBS wrote the paper, and CES, RBS, KG, and IA edited the manuscript. All authors read and approved the final manuscript.

Funding

This work was funded by Sarepta Therapeutics.

Availability of data and materials

The study data are confidential and thus not able to be shared.

Code availability

Not applicable.

\section{Declarations}

Ethics approval and consent to participate

The protocol was reviewed and approved by the New England Independent Review Board (NEIRB \#20201623).

Consent for publication

All participants agreed to their data being published in a journal article.

\section{Competing interests}

All authors declare that they have no potential conflicts of interest and report no disclosures. 


\section{Author details}

${ }^{1}$ DeltaQuest Foundation, Inc, 31 Mitchell Road, Concord, MA 01742, USA.

${ }^{2}$ Departments of Medicine and Orthopaedic Surgery, Tufts University Medical

School, Boston, MA, USA. ${ }^{3}$ Sarepta Therapeutics, Cambridge, MA, USA.

Received: 7 May 2021 Accepted: 7 October 2021

Published online: 20 November 2021

\section{References}

1. Post SG (2007) Altruism and health: perspectives from empirical research. Oxford, New York

2. Schwartz CE, Sendor M (1999) Helping others helps oneself: response shift effects in peer support. Soc Sci Med 48(11):1563-1575

3. Rhoades DR, McFarland KF (2000) Purpose in life and self-actualization in agency-supported caregivers. Commun Ment Health J 36(5):513-521

4. Midlarsky E, Kahana E, Post SG (2007) Altruism, well-being, and mental health in late life. In: Altruism and health: perspectives from empirical research. Oxford, New York, pp 56-69

5. Schwartz C, Meisenhelder JB, Ma Y, Reed G (2003) Altruistic social interest behaviors are associated with better mental health. Psychosom Med 65(5):778-785

6. Schwartz CE, Quaranto B, Bode R, Finkelstein JA, Glazer PA, Sprangers MA (2012) Doing good, feeling good, and having more: resources mediate the health benefits of altruism differently for males and females with lumbar spine disorders. Appl Res Qual Life 7(3):263-279. https://doi.org/ 10.1007/s11482-012-9165-y

7. Bevans M, Sternberg EM (2012) Caregiving burden, stress, and health effects among family caregivers of adult cancer patients. Jama 307(4):398-403

8. Klassen AF, Gulati S, Granek L, Rosenberg-Yunger ZR, Watt L, Sung L, Klaassen R, Dix D, Shaw NT (2012) Understanding the health impact of caregiving: a qualitative study of immigrant parents and single parents of children with cancer. Qual Life Res 21(9):1595-1605

9. Giovannetti ER, Wolff JL, Frick KD, Boult C (2009) Construct validity of the work productivity and activity impairment questionnaire across informal caregivers of chronically ill older patients. Value Health 12(6):1011-1017. https://doi.org/10.1111/j.1524-4733.2009.00542.x

10. Zarit SH, Reever KE, Bach-Peterson J (1980) Relatives of the impaired elderly: correlates of feelings of burden. Gerontol 20(6):649-655

11. Landfeldt $E$, Lindgren $P$, Bell CF, Guglieri M, Straub V, Lochmüller H, Bushby K (2016) Quantifying the burden of caregiving in Duchenne muscular dystrophy. J Neurol 263(5):906-915

12. van Andel J, Westerhuis W, Zijlmans M, Fischer K, Leijten FS (2011) Coping style and health-related quality of life in caregivers of epilepsy patients. J Neurol 258(10):1788-1794

13. Burke T, Elamin M, Galvin M, Hardiman O, Pender N (2015) Caregiver burden in amyotrophic lateral sclerosis: a cross-sectional investigation of predictors. J Neurol 262(6):1526-1532

14. Te Groen M, Bloem BR, Wu SS, Post B (2021) Better quality of life and less caregiver strain in young-onset Parkinson's disease: a multicentre retrospective cohort study. J Neurol 268(3):1102-1109

15. Okuda S, Tetsuka J, Takahashi K, Toda Y, Kubo T, Tokita S (2019) Association between sleep disturbance in Alzheimer's disease patients and burden on and health status of their caregivers. J Neurol 266(6):1490-1500

16. Burke T, Hardiman $O$, Pinto-Grau M, Lonergan $K$, Heverin M, Tobin $K$ Staines A, Galvin M, Pender N (2018) Longitudinal predictors of caregiver burden in amyotrophic lateral sclerosis: a population-based cohort of patient-caregiver dyads. J Neurol 265(4):793-808

17. Chahine L, Feldman R, Althouse A, Torsney B, Alzyoud L, Mantri S, Edison B, Albert S, Daeschler M, Kopil C (2021) Contribution of neuropsychiatric symptoms in Parkinson's disease to different domains of caregiver burden. J Neurol:1-12

18. Jain P, Subendran J, Smith ML, Widjaja E (2018) Care-related quality of life in caregivers of children with drug-resistant epilepsy. J Neurol 265(10):2221-2230

19. Ryder S, Leadley R, Armstrong N, Westwood M, De Kock S, Butt T, Jain M, Kleijnen J (2017) The burden, epidemiology, costs and treatment for Duchenne muscular dystrophy: an evidence review. Orphanet J Rare Dis 12(1):79
20. Mendell JR, Shilling C, Leslie ND, Flanigan KM, Al-Dahhak R, Gastier-Foster J, Kneile K, Dunn DM, Duval B, Aoyagi A (2012) Evidence-based path to newborn screening for Duchenne muscular dystrophy. Ann Neurol 71(3):304-313

21. Moat SJ, Bradley DM, Salmon R, Clarke A, Hartley L (2013) Newborn bloodspot screening for Duchenne muscular dystrophy: 21 years experience in Wales (UK). Eur J Hum Genet 21(10):1049-1053

22. Ciafaloni E, Fox DJ, Pandya S, Westfield CP, Puzhankara S, Romitti PA, Mathews KD, Miller TM, Matthews DJ, Miller LA (2009) Delayed diagnosis in duchenne muscular dystrophy: data from the Muscular Dystrophy Surveillance, Tracking, and Research Network (MD STARnet). J Pediatr 155(3):380-385

23. Pane M, Lombardo ME, Alfieri P, D'Amico A, Bianco F, Vasco G, Piccini G, Mallardi M, Romeo DM, Ricotti V (2012) Attention deficit hyperactivity disorder and cognitive function in Duchenne muscular dystrophy: phenotype-genotype correlation. J Pediatr 161(4):705-709

24. Sarepta Therapeutics (2020) Duchenne: a progressive, muscle-weakening disease. https://www.duchenne.com/disease-progression. Accessed March 32020

25. Hamdani Y, Mistry B, Gibson BE (2015) Transitioning to adulthood with a progressive condition: best practice assumptions and individual experiences of young men with Duchenne muscular dystrophy. Disab Rehabil 37(13):1144-1151

26. Landfeldt E, Edström J, Buccella F, Kirschner J, Lochmüller H (2018) Duchenne muscular dystrophy and caregiver burden: a systematic review. Dev Med Child Neurol 60(10):987-996

27. Verberkt HJ (2001) See me graduate. The Lancet 358:S26

28. Read J, Kinali M, Muntoni F, Garralda ME (2010) Psychosocial adjustment in siblings of young people with Duchenne muscular dystrophy. Eur J Paed Neurol 14(4):340-348

29. Yamaguchi M, Sonoda E, Suzuki M (2019) The experience of parents of adult sons with Duchenne muscular dystrophy regarding their prolonged roles as primary caregivers: a serial qualitative study. Disabil Rehabil 41(7):746-752

30. Lue Y-J, Chen S-S, Lu Y-M (2018) Factors affecting the health-related quality of life of caregivers of patients with muscular dystrophy. J Neurol 265(7):1548-1556

31. Nozoe KT, Kim LJ, Polesel DN, Hirotsu C, de Souza AL, Hachul H, Tufik SB, Tufik S, Andersen ML, Moreira GA (2017) Sleep pattern and spectral analysis of caregiver-mothers of sons with Duchenne muscular dystrophy, and an examination of differences between carriers and non-carriers. Sleep Med 32:114-121

32. Kenneson A, Bobo JK (2010) The effect of caregiving on women in families with Duchenne/Becker muscular dystrophy. Health Soc Care Commun 18(5):520-528

33. Abi Daoud MS, Dooley JM, Gordon KE (2004) Depression in parents of children with Duchenne muscular dystrophy. Pediatr Neurol 31(1):16-19

34. Magliano L, D'Angelo MG, Vita G, Pane M, D'Amico A, Balottin U, Angelini C, Battini R, Politano L, Group TGW (2014) Psychological and practical difficulties among parents and healthy siblings of children with Duchenne vs. Becker muscular dystrophy: an Italian comparative study. Acta Myol 33(3):136

35. Nozoe KT, Hachul H, Hirotsu C, Polesel DN, Moreira GA, Tufik S, Andersen ML (2014) The relationship between sexual function and quality of sleep in caregiving mothers of sons with duchenne muscular dystrophy. Sex Med 2(3):133-140

36. Schreiber-Katz O, Klug C, Thiele S, Schorling E, Zowe J, Reilich P, Nagels $\mathrm{KH}$, Walter MC (2014) Comparative cost of illness analysis and assessment of health care burden of Duchenne and Becker muscular dystrophies in Germany. Orphanet J Rare Dis 9(1):210

37. Atkinson R, Flint J (2001) Accessing hidden and hard-to-reach populations: Snowball research strategies. Soc Res Update 33(1):1-4

38. Hays RD, Bjorner JB, Revicki DA, Spritzer KL, Cella D (2009) Development of physical and mental health summary scores from the patient-reported outcomes measurement information system (PROMIS) global items. Qual Life Res 18:873-880. https://doi.org/10.1007/s11136-009-9496-9

39. National Institute of Neurological Disorders and Stroke (2010) User Manual for the Quality of Life in Neurological Disorders (Neuro-QOL) Measures, version 1.0.

40. Ryff CD (1989) Happiness is everything, or is it? Explorations on the meaning of psychological well-being. J Person Soc Psychol 57:1069-1081 
41. Measuring healthy days: population assessment of health-related quality of life (2000), vol 40. Centers for Disease Control and Prevention, Atlanta, GA

42. Schwartz CE, Powell VE, Eldar-Lissai A (2017) Measuring hemophilia caregiver burden: validation of the Hemophilia Caregiver impact measure. Qual Life Res 26(9):2551-2562. https://doi.org/10.1007/ s11136-017-1572-y

43. Schwartz CE, Zhang J, Su J (2019) Longitudinal construct validity of the Hemophilia Caregiver impact measure. Qual Life Res 28(7):1979-1987. https://doi.org/10.1007/s11136-019-02168-y

44. Jaffee KD, Liu GC, Canty-Mitchell J, Qi RA, Austin J, Swigonski N (2005) Race, urban community stressors, and behavioral and emotional problems of children with special health care needs. Psychiatr Serv 56(1):63-69

45. Sanders-Phillips K (1996) Correlates of health promotion behaviors in low-income Black women and Latinas. Am J Prevent Med 12(6):450-458

46. Hanmer J, Cherepanov D (2016) A single question about a respondent's perceived financial ability to pay monthly bills explains more variance in health utility scores than absolute income and assets questions. Qual Life Res 25(9):2233-2237

47. Schwartz CE, Zhang J, Stucky BD, Michael W, Rapkin BD (2019) Is the link between socioeconomic status and resilience mediated by reserve-building activities: Mediation analysis of web-based cross-sectional data from chronic medical illness patient panels. BMJ Open 9(5):e025602. https:// doi.org/10.1136/bmjopen-2018-025602

48. Reilly MC, Bracco A, Ricci JF, Santoro J, Stevens T (2004) The validity and accuracy of the work productivity and activity impairment questionnaire-irritable bowel syndrome version (WPAI:IBS). Aliment Pharmacol Ther 20(4):459-467. https://doi.org/10.1111/j.1365-2036.2004.02091.x

49. Reilly MC, Gerlier L, Brabant Y, Brown M (2008) Validity, reliability, and responsiveness of the work productivity and activity impairment questionnaire in Crohn's disease. Clin Ther 30(2):393-404. https://doi.org/10. 1016/j.clinthera.2008.02.016

50. Reilly MC, Lavin PT, Kahler KH, Pariser DM (2003) Validation of the dermatology life quality index and the work productivity and activity impairment-chronic hand dermatitis questionnaire in chronic hand dermatitis. J Am Acad Dermatol 48(1):128-130. https://doi.org/10.1067/ mjd.2003.128

51. Schwartz CE, Michael W, Zhang J, Rapkin BD, Sprangers MAG (2018) Assessing reserve-building pursuits and person characteristics: psychometric validation of the DeltaQuest reserve-building measure. Qual Life Res 27:423-436. https://doi.org/10.1007/s11136-017-1694-2

52. U.S. Department of Labor/Employment and Training Administration (USDOL/ETA) (1998) Occupational Information Network (O*NET) U.S. Department of Labor/Employment and Training Administration (USDOL/ ETA), Washington, D.C.

53. Tsacoumis S, Willison S (2010) O*NET Analyst Occupational Skill Ratings: Procedures. National Center for O*NET Development, Raleigh, NC

54. Reed BR, Mungas D, Farias ST, Harvey D, Beckett L, Widaman K, Hinton L, DeCarli C (2010) Measuring cognitive reserve based on the decomposition of episodic memory variance. Brain J Neurol 133(Pt 8):2196-2209. https://doi.org/10.1093/brain/awq154
55. Rapkin BD, Schwartz CE (2004) Toward a theoretical model of qualityof-life appraisal: Implications of findings from studies of response shift. Health Qual Life Outcomes 2(1):14

56. Bochner B, Schwartz CE, Garcia I, Goldstein L, Zhang J, Rapkin BD (2017) Understanding the impact of radical cystectomy and urinary diversion in patients with bladder cancer: treatment outcomes clarified by appraisal process. Qual Life Res 26(Suppl 1):6

57. Schwartz CE, Michael W, Rapkin BD (2017) Resilience to health challenges is related to different ways of thinking: mediators of physical and emotional quality of life in a heterogeneous rare-disease cohort. Qual Life Res 26(11):3075-3088

58. Schwartz CE, Stark RB, Rapkin BD, Selbe S, Michael W, Stopka T (2020) Cognitive habits linked to resilience: Surprising commonalities across the United States. J Commun Med Public Health Rep. https://doi.org/10. 38207/JCMPHR20202

59. IBM (2019) SPSS Statistics for Windows. 26 edn. IBM Corp., Armonk, NY

60. Cohen J (1992) A power primer. Psychol Bull 112:155-159

61. Tessitore A, Marano P, Modugno N, Pontieri FE, Tambasco N, Canesi M, Latorre A, Lopiano L, Sensi M, Quatrale R (2018) Caregiver burden and its related factors in advanced Parkinson's disease: data from the PREDICT study. J Neurol 265(5):1124-1137

62. Rapkin BD, Schwartz CE. Toward a theoretical model of quality-of-life appraisal: Implications of findings from studies of response shift. Health Qual Life Outcomes. 2004;2:14.

63. Sisk RJ (2000) Caregiver burden and health promotion. Int J Nurs Stud 37(1):37-43

64. Schwartz CE, Rapkin BD, Healy BC (2016) Reserve and reserve-building activities research: key challenges and future directions. BMC Neurosci 17:62. https://doi.org/10.1186/s12868-016-0297-0

65. Aguiar AS Jr, Castro AA, Moreira EL, Glaser V, Santos AR, Tasca Cl, Latini A, Prediger RD (2011) Short bouts of mild-intensity physical exercise improve spatial learning and memory in aging rats: involvement of hippocampal plasticity via AKT, CREB and BDNF signaling. Mech Ageing Dev 132(11-12):560-567. https://doi.org/10.1016/j.mad.2011.09.005

66. Barulli D, Stern Y (2013) Efficiency capacity, compensation, maintenance, plasticity: emerging concepts in cognitive reserve. Trends Cogn Sci 17(10):502-509. https://doi.org/10.1016/j.tics.2013.08.012

67. Cotman CW, Berchtold NC (2002) Exercise: a behavioral intervention to enhance brain health and plasticity. Trends Neurosci 25(6):295-301

68. Lovden M, Wenger E, Martensson J, Lindenberger U, Backman L (2013) Structural brain plasticity in adult learning and development. Neurosci Biobehav Rev 37(9):2296-2310

69. Schwartz CE, Peng CK, Lester N, Daltroy LH, Goldberger AL (1998) Selfreported coping behavior in health and disease: assessment with a card sort game. Behav Med 24(1):41-44

\section{Publisher's Note}

Springer Nature remains neutral with regard to jurisdictional claims in published maps and institutional affiliations. 